Competitive Work Environments and Social Preferences: Field experimental evidence from a Japanese fishing community

by

Jeffrey Carpenter, Middlebury College

Erika Seki, University of Aberdeen

July 2005

MIDDLEBURY COLLEGE ECONO MICS DISCUSSION PAPER NO. 05-13

DEPARTMENT OF ECONOMICS

MIDDLEBURY COLLE GE

MID D LEBURY, VERMONT 05753

http:/ / www.middlebury.edu/ econ 


\title{
Competitive Work Environments and Social Preferences: Field experimental evidence from a Japanese fishing community*
}

\author{
Jeffrey Carpenter ${ }^{\dagger} \quad$ Erika Seki $i^{\frac{1}{+}}$
}

July 18,2005

\begin{abstract}
Models of job tournaments and competitive workplaces more generally predict that while individual effort may increase as competition intensifies between workers, the incentive for workers to cooperate with each other diminishes. We report on a field experiment conducted with workers from a fishing community in Toyama Bay, Japan. Our participants are employed in three different aspects of fishing. The first group are fishermen, the second group are fish wholesalers (or traders), and the third group are staff at the local fishing coop. Although our participants have much in common (e.g., their common relationship to the local fishery and the fact that they all live in the same community), we argue that they are exposed to different amounts of competition on-the-job and that these differences explain differences in cooperation in our experiment. Specifically, fishermen and traders, who interact in more competitive environments are significantly less cooperative than the coop staff who face little competition on the job. Further, after accounting for the possibility of personality-based selection, perceptions of competition faced on-the-job and the treatment effect of job incentives explain these differences in cooperation to a large extent.
\end{abstract}

Keywords: Field experiment, cooperation, social disapproval, social preference, competition, Japan, fishing

JEL codes: C90, C93, H41, M54, Z13

\section{Introduction}

Most jobs require workers to perform a menu of tasks including individual and cooperative tasks. Individual tasks increase individual productivity while co-

\footnotetext{
*We thank Peter Matthews, John List, and two referees for comments, Kiyoshi Yokoo for research assistance, and the National Science Foundation (CAREER 0092953) for financial support.

†Department of Economics, Middlebury College \& IZA; jpc@middlebury.edu.

†epartment of Economics, University of Aberdeen; erika.seki@abdn.ac.uk.
} 
operative tasks improve the productivity of workers as a whole. In some cases these tasks are complementary so that team production might be required for anything to be produced. In other cases effort exerted to perform the two tasks is substitutable and productivity-enhancing cooperation might be as simple as one worker sacrificing her own performance to help another. However, as personnel economics has pointed out, the ability of a firm to take advantage of strategic complementarities embodied in the production process depends to a great extent on the choice of compensation scheme. For example, Lazear (1989), Prendergast (1999) and Rob and Zemsky (2002) point out that workers who face tournament incentives for promotion, or competition from other workers in general, will be less inclined to cooperate. In fact, workplace competition often provides an incentive to sabotage the efforts of others (Chen, 2003). Recognizing this problem, Holmstrom and Milgrom (1991) suggest using low powered incentives on the individual tasks to balance the incentives between competing tasks. At the same time, Rotemberg (1994) moving in the opposite direction, shows that strategic complementarities as arise under team production, for example, provide a necessary condition for altruism to evolve among co-workers. He further suggests that such between-worker altruism can increase productivity.

Despite the interesting balance of incentives provided by introducing competition in the workplace - on one hand individual workers may exert more effort to win promotion or make more money while on the other overall production might suffer because of the lack of cooperation among workers - there has been remarkably little empirical work estimating the effect of competition on workplace cooperation. One obvious reason is that it is hard to measure cooperation between workers. This is why field experimental measures of social preference are potentially useful. The one noteworthy non-experimental study is Drago and Garvey (1998) who show that Australian workers tend to share tools and equipment less often when compensation is allocated more competitively.

There has also been little work on the relationship between compensation schemes and the extent to which workplace social preferences arise. One exception is Burks et al. (2005) who find that the distribution of cooperative social preferences among bicycle messengers can be predicted by whether riders are paid on commission or not. Consistent with Rotemberg (1994), those messengers who are paid on commission were $12 \%$ more likely to be classified as egoists in a sequential prisoner's dilemma experiment than those who are paid hourly or are members of coops that share revenues. Further, controlling for selection into jobs, performance pay couriers were still $11 \%$ more likely to be classified as an egoist. We contribute to this thin literature by using a field experiment to measure social preferences for cooperation among workers who experience differing degrees of strategic complentarity and face varying degrees of on-the-job competition. ${ }^{1}$

\footnotetext{
${ }^{1}$ We have recently also been made aware of the complementary study by Bandiera et al., (2004) who examine the effect of relative (versus piece rate) incentives on productivity and cooperation. In their study cooperation is measured as the difference in observed effort from the Pareto optimal effort level. They find that cooperation depends on work group size, work
} 
Our workers are all engaged in fishing in Toyama Bay which opens from the Honsyu main island into the Sea of Japan. This means that by design we control for any differences in regional cultural norms or industrial practices by limiting our attention to one fishery, but our participants en gage in one of three different tasks. One group fishes for various species in teams of four or five, another group runs the coop where all the fish are auctioned to the third group of traders who wholesale the fish to retail outlets as far away as Tokyo and Osaka. While our experiment covers workers employed in three different activities, we actually have four distinct groups who face differing levels of on-the-job competition. One subgroup of the fishermen, comprising approximately half the group, fish competitively, each boat catching and selling its fish independently of the others. In contrast, the other half of the fishermen have formed a collective in which revenues and many expenses are pooled across boats. This also implies that according to Rotemberg (1994) our pooling fishermen, who face a second degree of strategic complementarity, should feel added pressure to be other-regarding compared to the nonpoolers.

The comparison of poolers to nonpoolers provides a clean test of the Rotemberg (1994) conjecture because most of the elements of the production process are common except those elements related to the fact that the poolers share revenues (and many operating costs). Additionally, the strategic complemantarities between pooling boats are clear. At the same time, variation in competition onthe-job provides a broader link between all our participants. For this reason we consider analyzing the effect of competition our primary goal and testing the Rotemberg hypothesis our secondary goal.

Considering our primary goal, clearly the pooling arrangement will reduce competition within the subgroup of poolers because it dramatically compresses the distribution of compensation (Lazear, 1989). By comparison, members of the nonpooling subgroup face competition from both the other subgroup and the other boats in their subgroup. Likewise, traders face intense competition on the job from the other traders. In fact, the encounter among nonpoolers has been analyzed using a modified Cournot model (Seki, forthcoming) while the interaction between the traders might be conceptualized in a Betrand price competition model. Coop staff, on the other hand, face little competition because the organizational structure of the coop is relatively flat and there are few incentives or opportunities to outdo other staff members.

Based on the material incentives associated with their jobs, we categorize our participants along a competition continuum: traders and nonpoolers face high levels of on-the-job competition, poolers face medium levels, and coop staff face low levels. As we will see, this classification is confirmed to some degree by survey responses that we also collected from our participants. In addition, we find that cooperation levels in our artefactual field public goods game correlate with our assertions about the competitiveness of the workplace. ${ }^{2}$ Comparing

group heterogeneity, and the ability to engage in peer monitoring.

${ }^{2}$ We classify our field experiment as artefactual because our subject pool is nonstandard, but the experiment was conducted in a improvised lab setting. See Harrison and List (2004) or Carpenter et al. (2005) for more on the classification of field experiments. 
contribution levels from games played within groups we find that, non-pooling fishermen cooperate the least with each other, traders and poolers are slightly more cooperative, but staff members cooperate the most. With respect to the Rotemberg (1994) idea that strategic complementarity should correlate with the evolution of social preferences on-the-job, we do find that poolers are more cooperative than non-poolers, however the difference in point estimates never rises to the level of significance especially when one accounts for demographic effects and the impact of workplace competition.

Most importantly, however, when we directly link cooperation to our surveyed measures of on-the-job competition we find that higher levels of perceived competition are associated with lower levels of cooperation in the experiment and the inclusion of this regressor absorbs some of the variation in cooperation previously attributed to indicator variables marking the groups. In other words, we have evidence that part of the reason we see differences in cooperation by job category is because workers feel more competitive towards each other in some jobs.

We proceed by first providing more of the institutional details of fishing in Toyama Bay. We then describe our field protocol and present general results from the experiment. In the fifth section we bolster our general finding by more explicitly linking workplace competition to cooperation in our experiment which in Carpenter and Seki (2004) we show correlates with cooperation and productivity on the job, at least for the fishermen. Before concluding, we offer some evidence of a treatment effect of exposure to different jobs on worker social preferences.

\section{Fishing in Toyama Bay}

Toyama Bay which opens into the Sea of Japan from the west coast of the Honsyu main island of Japan, is known for a large variety of highly valued fish species because of the complex structure of the sea bottom and a mixture of currents that flow into the bay. There are 16 small fishing communities situated along the coast including our base, Shinminato. Japanese fisherfolk organize themselves into local Fisheries Cooperative Associations (FCAs) that formed in the wake of traditional fishermen guilds at the beginning of the 20th century (Yamamoto and Short, 1991). FCAs control fish auctions, provide fishing materials (e.g., fuel, ice, and packing materials), manage saving accounts for the members, organize regular meetings and training for the member fishermen, along with regulating the local fisheries. FCAs organize auctions to sell the day's haul to registered merchants, retailers, and processors. These auctions are considered one of the most important functions of the FCAs, not only because they generate more revenues for the fisherfolk by extracting resource rents, but also because they act as a venue for fisherfolk discussions (Hasegawa et al., 1991). Sales revenues, net of commissions to the FCAs, are transferred into the savings accounts of the individual member fishermen. Over 500 fishers belong to the Shiminato FCA which employs 14 full-time staff members (three 
females and 11 males). Most male staff members are directly involved in fish auctions, while female staff members are responsible for processing daily sales information and managing the financial accounts of the members. Other tasks, including the daily cleaning of the auction premises and the FCA building, are shared among all the staff members.

With regard to fishery regulations, local FCAs do not only implement and enforce national and prefectural legislation, they also devise complementary regulations that are designed specifically to deal with evolving local conditions. Within each FCA, fishermen are grouped according to the species they target and/or the fishing technologies that they use. The fishermen that participated in our study belong to the small-scale trawlers group. All 12 boats belong to the group specializing in fishing Shiroebi (Japanese glass shrimp) between April and October, and crabs and cold-water shrimp (Akaebi) during the rest of the year.

What is important to reiterate is that during the Shiroebi season, the 12 boats are organized into two groups based on whether or not they pool their catch. One group, consisting of seven boats and 30 fishermen ( 7 skippers, 21 crew members, and 2 onshore helpers) whom we call poolers, have shared both income and operating expenses since the beginning of the 1960s. ${ }^{3}$ The second group, which we call the nonpoolers, consists of 5 fishing boats and 30 fishermen ( 5 skippers and 25 crewmen). Members of this second group do not pool income or expenses.

Each Shrioebi fishing boat is staffed with one skipper and three or four crewmembers. The skippers (often the boat owners) navigate the boat and supervise the operation of all the fishing equipment (e.g., echo sounder, satellite navigation, fishing nets), and make all final decisions concerning the operation. Although fishing operations are highly mechanised, the experience of the skipper and coordination among the crew members are believed to be important for better performance. For instance, in addition to the use of an echo sounder and global positioning system to detect and locate concentrations of shrimp, knowledge of the bay's seabed topography increases the accuracy of a search and prevents the costly loss of nets. Many aspects of handling the fishing equipment are done manually and require coordination among the crewmembers. Given the large size of the nets (approximately 200 meters by 100 meters), setting and lifting a net requires coordinated maneuvering by two or more crew members. Additionally, handling the stock post-harvest requires quick and coordinated action to maintain freshness and quality.

As a matter of tradition, the division of income between the owner and crewmembers is almost identical across all boats (poolers and nonpoolers). Total income is divided into $7 \frac{1}{2}$ shares of which $3 \frac{1}{2}$ shares accrue to the boat owner and 4 shares are divided equally among a skipper and crewmembers. Among the poolers there are two retired skippers and another crewmember who handle the fish on-shore. They are responsible for offloading and weighing the shrimp.

\footnotetext{
${ }^{3}$ More specifically, poolers share both income and operating expenses, but in terms of capital investments, only costs of nets are borne by the whole group; boats and other equipment are individually financed.
} 
These on-shore helpers receive the same income as the other crewmembers. As for the nonpooling group, these on-shore tasks are carried out by the wives of the skippers and their shares are accounted for in the owners' share. The wives of the nonpooling skippers are therefore considered nonpoolers in our experiment.

Cooperative staff members are remunerated according to a fixed wage system akin to the public sector. Their wages rise with seniority and they are given a relatively generous pension benefit.

There are approximatley 22 fish traders who participate in daily auctions held at the Sinminato FCA. Most of them, except a few employees of a supermarket chain, are descendants of traditional local fish merchant families. All traders are involved in fish processing as well as wholesaling or retailing, and many of them also participate in auctions held at other FCAs along Toyama Bay. Shiminato fish traders are known for their competitive business practices. ${ }^{4}$

\section{$3 \quad$ Field Experimental Design}

Because we are interested in differences in on-the-job levels of cooperation, we employed a standard social dilemma experiment, the voluntary contribution mechanism (VCM), which elicits contributions to a public good. Each of the eight sessions was run within one of the populations we sampled so that we gathered measures of cooperation among people who naturally interact with each other at work. In addition to running sessions of all nonpoolers, all poolers, all traders, and all staff, we also ran two sessions with college students from Toyama prefecture to link our results to the standard laboratory literature and demonstrate that our field results are not an artifact of our procedures.

While the first five rounds of our ten-round VCM use a standard protocol, the second five rounds employ an innovation first used in Carpenter et al. (2004a) and Carpenter et al. (2004b). ${ }^{5}$ In these five rounds, participants are allowed to show social disapproval for the contribution levels of the group. Social disapproval is a costly signal sent by individual players anonymously to show that they are unhappy with how much the group contributed on the last round. In practice, the signal was a number of unhappy faces displayed for the group at the beginning of rounds 7-10 that illustrated the number of dissatisfied group members. We included this design feature as an auxiliary test of whether on-the-job competition predicted rates of norm enforcement among groups of co-workers.

The details of the strategic environment are as follows. ${ }^{6}$ Participants interacted anonymously (the experiment was single-blind) in non-changing groups of four. Each participant started each round with an endowment of ten 50-yen

\footnotetext{
${ }^{4}$ There are a number of anecdotal stories that suggest a competitive work environment among the Shinminato traders. For instance, one of the traders invented a viable system to shell and freeze shiroebi allowing him to supply the lucrative urban markets. While he did not share this information, his competitors gradually found out. Even now, the trader workshops and storage facilities are kept covered so that their work cannot been observed by the others.

${ }^{5}$ However, the protocol resembles Masclet et al. (2003).

${ }^{6}$ See the appendix for the instructions.
} 
coins (approximately $\$ 4.30$ at the time). We used real money and high stakes to make the decision as salient as possible. The marginal per capita return on the public good was 0.5 so free riding was the dominant strategy. Free riding remained the dominant strategy during the social disapproval rounds because it cost 10 yen to display an unhappy face. This cost assured unhappy faces would not be a component of any subgame perfect strategy (i.e., social disapproval is just a second-order public good). More importantly however, the unhappy faces carried no monetary implications for the other group members and therefore they did not provide free riders with an incentive to cooperate.

At the beginning of each round, participants (sitting behind field-improvised blinds to provide privacy) were given small envelopes with ten 50-yen coins inside. Participants then took out as many coins as they wanted to keep for themselves and put them in another larger opaque envelope. Once everyone had made this decision, an experimenter came around to collect the contributions in the smaller envelopes. Group total contributions were then calculated and reported to the participants on sheets of paper that listed individual contributions (in random order), the group total contribution, and the payoff from the public good. During the social disapproval rounds, participants were given additional slips of paper at the feedback stage on which they indicated whether they wanted to pay 10 yen to show disapproval or not. If any unhappy face signals were purchased within a group, they were stamped on the endowment envelopes at the beginning of the next round. Hence, at the beginning of rounds 7-10 participants saw between 0 and 4 unhappy faces on their endowment envelopes. After the experiment was completed, participants filled out a survey that included demographics, a few standard personality questions, and questions about their work.

We summarize the character istics of our participants in Table 1. Overall, we had 77 participants: 26 were students, 13 were nonpoolers, 14 were poolers, 12 were traders, and the remaining 12 were coop staff members. ${ }^{7}$ The number of women participants varies by population. At one extreme there were no women pooling fishermen, but there were a few women who work for the nonpooling boats. The fisherfolk tend to be older than the traders and coop staff and the latter two groups tend to be in their mid-thirties. High (or Occupational) School is an indicator variable which takes the value of one if high school is the participant's highest level of educational attainment. While there is some variation among the workers, approximately half stopped after high school (many of the rest left earlier).

We also had participants respond to two personality scales: a version of the Rotter (1966) questionnaire which is thought to measure the internal versus external orientation of participants and a four-question cooperation scale. Internally oriented participants tend to believe that they are largely respon-

\footnotetext{
${ }^{7}$ Notice that the participant numbers by population are not all evenly divided by four. In the few cases where we could not get full groups of four we relied on the fact that the participants did not know what group they were in and formed "shadow members." These randomly chosen participants contributed to their own group but their behavior was counted in another group to get the total up to four persons.
} 
sible for their own fates while externals believe that life tends to "happen to them." For example, internals believe, "my success depends on ability rather than luck" while externals think people are successful because they are lucky. In our implementation, participants stated whether they agreed or disagreed with six statements and their Rotter score was simply the sum of these responses. Responses that indicated internal or ientation were coded as +1 and those indicating external orientation were coded as -1 . As one can see the poolers and to a lesser degree, staff members tended to be more internally oriented while the non-poolers and traders tended to be externally oriented.

The cooperation scale asked whether participants agreed, disagreed, or had no reaction to the following four statements: 1) It is virtuous to compete; 2) It is virtuous to cooperate; 3 ) One must reciprocate kindness; 4) People should revenge wrongs done to them. One's score increased by one for agreeing with 2 and 3 and for disagreeing with 1 and 4 . One's score decreased by one for agreeing with 1 and 4 and disagreeing with 2 and 3. Based on the last row of Table 1, we see that the poolers had the most cooperative dispositions followed by the nonpoolers. In fact, poolers are significantly more cooperative than students, staff, and traders based on this scale, however, none of the other differences are significant at the $10 \%$ level.

\section{General Experimental Results}

Overall, pooling the ten rounds of data, our participants contributed an average of 4.64 coins (out of a 10 coin endowment). When we split the data by sampled population we find interesting differences in the central tendencies of the contribution data. Students contribute by far the least, 3.15 coins, on average, and the worker population means can be ordered as follows: nonpoolers $(4.59)<$ poolers $(5.14)<$ traders $(5.56)<\operatorname{staff}(6.46) .^{8}$ The Mann-Whitney Rank Sum test indicates that each link in this ordering is significant at the $5 \%$ level or better except the pooler-trader difference. To get a better sense of the distribution of contribution decisions, Figure 1 presents an overall histogram of contributions pooled over the ten rounds and individual histograms from each sample. As one can see there are interesting differences in the distributions. For example, the students are more likely to contribute nothing than any of the other groups and the norm of contributing half only arises among the fisherfolk. ${ }^{9}$

Because pooled histograms mask any dynamics in contribution choices, in Figure 2 we present average contributions by round for each of our samples. There are a number of interesting dimensions to these graphs. First while the students, nonpoolers and traders show significant end game effects (i.e., contributions drop dramatically in the last few rounds), poolers and staff members do

\footnotetext{
${ }^{8}$ Our student contribution rates seem comparable but slightly lower than those reported in Yamagishi (1986) or Kiyonari et al. (2000).

${ }^{9}$ Despite the students being more likely to contribute nothing, if we look at average positive contributions (i.e., we drop the zeros) the ordering remains the same: $\operatorname{Stu}(4.26)<\mathrm{NP}(4.78)$ $<\mathrm{P}(5.5)<\mathrm{T}(6.23)<\mathrm{Sta}(6.51)$.
} 
not. In fact, the poolers show increasing contributions once social disapproval is allowed and the staff levels of cooperation increase throughout the experiment. Another more subtle difference in the graphs appears when one focuses on the regime change between rounds 5 and 6 . After social disapproval is initiated, contributions in each sample except the nonpoolers increase at least for a short while.

The non-parametric Mann-Whitney test does not account for the fact that our experiment generates a panel of contribution data. To account for individual heterogeneity we regress contribution choices on sample indicators and include individual level random effects. On top of this we also include round fixed effects to account for any shared time trends in the data. The results are reported in column (1) of Table 2. ${ }^{10}$ Each group of workers contributes significantly more than our baseline - the students. Further, the magnitudes of the coefficients are roughly in line with our expectations, given the amount of on-the-job competition faced by the workers in each group. On average, nonpoolers contribute just 2.06 coins more than students, traders contribute 2.99 more, poolers contribute 2.45 more, and staff members contribute 4.02 more. Given the average student contribution is 3.15 coins, it appears that staff members are more than twice as cooperative with each other as students are. ${ }^{11}$ Using $\chi^{2}$ tests we can examine the degree to which the point estimates are different and how well our contributions data line up with our expectations based on competitiveness of each job. At the $5 \%$ level, the nonpooler-staff and pooler-staff coefficients are different so there is some additional support for the expected ordering.

Another advantage of running regressions with our contribution data is that we can add control variables which, at a minimum, should help counteract any possible non-random assignment to population. For example, while we are happy, as a first step, to discover differences in cooperative behavior that correspond to differences in on-the-job competition, it may be hard to say much about the mechanism underlying the differences. On one hand, it could be that competition on the job affects social preferences for cooperation (as seen in the lab in Carpenter, 2005), but an equally plausible explanation is that competitive people select into more competitive environments.

While selection could be a factor, there are historical and institutional reasons why we think it is not a strong force in our results. Among the fishermen, there is a rich narative that we detail in Carpenter and Seki (2004) of how there came to be two groups of fishermen. The "upshot," however, is that the poolers and their ancestors have been fishing for shiroebi since the 18th century. Pooling (for the poolers) came about in the 1960s initially as a best response to income fluctuations and externalities inflicted on each other such as damaging each oth-

\footnotetext{
${ }^{10}$ One can also see that the individual random effects account for $21 \%(\mathrm{p}<0.01)$ of the variation in contributions (i.e., rho $=0.21$ ).

${ }^{11}$ We concede that restricting "like types" to play with each other may exaggerate the differences in contributions. However, these sorts of peer effects are naturally occurring and part of what we are trying to capture in our experiment. It would be interesting to compare these data with data from experiments in which participants were randomly assigned (across job types) into groups to measure cooperation with other workers. However, this is not the focus of the current study.
} 
ers nets and the inefficient use of the fishing grounds (Platteau and Seki, 2001). In particular, the pooling arrangement enabled the fishermen to maximise their surplus by price discriminating among the buyers (Seki, forthcoming). In sum, there are many reasons to consider pooling as an economic choice of all the people fishing in the 1960s for this shrimp, rather than some process of differential selection into (or away from) pooling by some due to their competitiveness. Put differently, pooling was originally needed because the fishermen were not $a$ priori cooperative enough to overcome various coordination problems.

The nonpoolers originally fished for a different shrimp species that became less economically lucrative in the early 1990s. After 6 years of negotiations, the nonpoolers were allowed to fish for shiroebi with the poolers. This resulted in the end of the pooler monopoly for shiroebi in 1992 but the pooling arrangement did not fall apart. Part of the reason why the pooling arrangement has been stable is that most skippers simply adopt whatever compensation scheme their fathers used. This implies that unless personality (i.e., competitiveness in particular) is completely inherited from one's father (who as we already suggested adopted pooling for economic not personality reasons), we should also not see sorting of new fishermen into jobs based on personal competitiveness. In fact, most traders and some of the coop staff members also hold their jobs because of traditional family ties.

To further assuage the reader, in column (2) of Table 2 we add an indicator for whether social disapproval was allowed, a female indicator, age and age ${ }^{2}$ (a la List, 2004), whether the participant's highest level of education was high school, the participant's Rotter score and the cooperation scale. The last two regressors in particular were added to partially control for differences in attitudes towards competition and cooperation that might be stable personality factors causing workers to chose one job over another. In this specification none of the demographics gain traction. However, in the specification in column (3) which we retrun to in some detail in section 5 , we see that contributions are concave in age which is similar to what Carpenter et al. (2004a) found in Vietnam but the opposite of what List (2004) found in the United States and both the Rotter score and the cooperation scale are significant. Internals appear to be less cooperative $(\mathrm{p}<0.05)$, and those who score higher on the cooperation scale do contribute significantly more $(\mathrm{p}<0.05)$.

Before moving on, we briefly examine the social disapproval data. Figure 3 presents time series of the average predicted probability that an individual will show social disapproval, controlling for the contributions of the other group members. ${ }^{12}$ One might expect the disapproval rates to be high for the students because their contributions are so low. However, notice that the graphs in Figure 3 control for how much the other group members contribute so it appears that students use the disapproval mechanism more in general. While Figure 3 reveals interesting differences in the use of social disapproval (e.g., traders and poolers barely use it at all while nonpoolers and staff members do), the levels do not

\footnotetext{
${ }^{12}$ Specifically, the values plotted in Figure 3 are the average predicted values by population from the following probit regression: $\operatorname{Pr}\left[D_{i, t}=1 \mid C_{-i, t}\right]=\alpha+\beta(C-i, t)+\epsilon_{i, t}$ where $D_{i, t}$ is a disapproval indicator and $C_{-i, t}$ is the total contribution by the other members of the group.
} 
seem to map as well onto differences in on-the-job competition.

In Table 3 we report the results of random effect probit regressions to assess differences in the likelihood of disapproval by population. In the uncontrolled regression (1) we see that each coin contributed by the other group members reduces the likelihood that another group member will show disapproval by a modest $3 \%$ (n.s.) and that traders and poolers use disapproval significantly less than students. Comparing the point estimates in column (1) we find that poolers and traders disapprove significantly less than staff members $(\mathrm{p}<0.05$ and $\mathrm{p}<0.10$, respectively). In column (2) we add the controls and find that these changes dramatically increase the marginal effects associated with nonpoolers, poolers, and traders. Now all workers, with the exception of staff members, disapprove significantly less than students, controlling for how much their group contributed. As with the contribution data, the demographics contribute little to the analysis. The one exception is that we find that older participants robustly show disapproval more often.

In sum, our experiment reveals interesting differences in behavior between students and workers and between workers. While the disapproval results are interesting, the focus of the paper is on the contribution data because this is where personnel economics provides crisp predictions. In line with our expectations, we find that those jobs that foster more competition between workers are associated with lower levels of cooperation. At the same time, we find little support for the Rotemberg (1994) hypothesis that workers engaged in team production will act more altruistically towards each other. In the next two sections we extend these basic results by discussing the importance of self-reports of competition on the job and the treatment effect of workplace incentives.

\section{Competitive environments and worker coop- eration}

At this point our evidence for the effect of competition on the cooperativeness of workers is circumstantial. We have shown that contribution levels in our field experiment are ordered as we would expect given the levels of on-thejob competition that are inherent in fishing, trading and being a staff member. However, we still do not have a direct link between competition and cooperation. Indeed, what might really be important is the amount of perceived competition felt by our participants not the incentives they face. To build a more convincing case we conclude by offering direct evidence in the form of surveyed attitudes of the participants towards each other. Specifically, in our post-experiment survey we asked our participants to respond (in the fisherfolks case) to the following statement, "I consider my fellow fishers:" with their choice of: (1) as family members, (2) as friends, (3) as strangers, and (4) as competitors. Each sample responded to an appropr iately worded statement and the distribution of responses by sample are collected in Table 4 . Because some of the participants checked more than one response, the frequencies in Table 4 do not all add up 
to one.

Considering just the workers, it is interesting that the nonpoolers, who we consider to face a lot of competition on the job, consider none of the other fisherfolk as family and $69 \%$ of them consider the other fisherfolk as competitors. Similarly, the traders consider none of the other traders as family and $42 \%$ of them consider the other traders as competitors. By contrast $21 \%$ of the poolers consider the other fisherfolk as family and only $14 \%$ see the others as competitors. At first glance the coop staff seem to break the correlation between workplace incentives and perceptions of on-the-job competition because $42 \%$ of them consider the other staff members to be competitors, but another $42 \%$ consider the other staff members to be like family. This suggests that the staff members perceive a sort of friendly or healthy competition compared to the more intense competition felt by the traders and the nonpoolers, in particular. Overall, the perceptions of competition seem to line up rather well with the incentives implicit in the different jobs.

To construct a measure of perceptions of competition on-the-job we created an indicator variable called competitive work environment which simply takes a value of zero if a participant considered his fellow workers as either family or friends and a value of one otherwise. This allows us to separate the friendly staff competition from the intense competitive feelings of the nonpoolers and traders. $^{13}$ Returning to Table 2, we see our main result. Adding the competitive work environment indicator in column (3) reveals a highly significant association: participants who perceive their work environment to be competitive contribute significantly fewer coins, 1.53 fewer, on average. Further, adding the competitive work environment indicator compresses the difference in the point estimates for the different jobs which suggests that part of the variation in contributions previously associated with differences in jobs are actually due to differences in levels of perceived on-the-job competition associated with the different jobs. ${ }^{14}$ To make the latter point more forcefully, Table 5 summarizes $\chi^{2}$ tests for differences in the job category indicator variables for columns (2) and (3) of Table 2. In other words, if controlling for perceptions of on-the-job competition does partially explain why we see differences in contribution rates by job, then the second $\chi^{2}$ statistics that come from column (3) should be lower than the first ones from column (2) because the difference in the point estimates

\footnotetext{
${ }^{13}$ Adding three of the four indicator variables does not perform quite as well as using the competitive work environment indicator, but we are convinced this is because the competitor indicator can not discern the qualitative difference between the staff response and the response of the other participants.

${ }^{14}$ One potential problem with column (3) of Table 2 (or columns (3) and (4) of Table 3) is that cooperation and competitive attitudes could be endogenous. In unreported regressions, we tried to instrument competitive attitudes but none of the instruments we tried were particularly strong. Instrumenting for competitive attitudes, however, will be hard in any case because it will always be difficult to satisfy the exclusion restrictions given we still know remarkably little about what determines play in the VCM. Based on Ledyard (1995) we tried to use a participant's sex because the evidence on whether there are sex-differences in contributions is not robust. However this instrument is weak (the raw correlation between Female and Competitive Work Environment is -0.01) as was another more defensible instrument, the number of actual "competitors" our participants faced on-the-job.
} 
will fall. Indeed, in each case, except the pooler-trader difference, the second $\chi^{2}$ is lower and in three cases the reduction in the difference is enough to remove or lower the significance of the statistic.

Although social disapproval is not the focus of the paper, we report the same analysis using columns (3) and (4) of Table 3 and Table 6. Column (3) shows that perceptions of a competitive work environment are positively associated with showing social disapproval but the rather large marginal effect is not significant $(\mathrm{p}=0.15)$. However, when we break the indicator into its components, consider others as family or friends in column (4) we see the same sort of compression of the job category marginal effects as we saw in the contribution data. In fact, in column (4) all four job indicators are now significant, as is the "consider others as friends" indicator. In Table 6 we see that five of the six $\chi^{2}$ statistics associated with column (4) are lower and the significance of any difference in the point estimates falls when we control for perceived competition on-the-job.

\section{Treatment Effects of Different Jobs}

In section 4 we made a case for why we don't expect that our main results can be explained by the differential selection of competitive personality types into some jobs. Not only are there strong institutional reasons why differential selection is not likely, we also control, to some extent, for personality differences in our main regressions. Putting selection aside, it might still be interesting to assess whether there are any treatment effects of the different job types and their incentives on the social preferences of our participants. Luckily, we also collected experience data from our participants that allows us to conduct a very straight-forward treatment analysis. In column (4) of Table 2 we report one final contribution regression in which we add years of participant experience and interactions of experience with the different job categories. ${ }^{15}$ The interpretation of the stand-alone experience coefficient is the effect of more experience in our control group (the students) on contributions. As one can see, the students tend to become more cooperative with experience $(\mathrm{p}<0.10)$.

For our purposes, the interaction terms are more interesting. Compared to the student baseline, each of our job categories experience significant declines in cooperativeness with experience. In addition some of the differences in these treatment effects make sense. The nonpoolers are subject to significantly greater reductions in cooperativeness than the poolers and staff members $(p<0.01$ and $p<0.05$, respectively). In fact, combining the baseline and differential effects suggest that, while students become more cooperative with experience in their environment and poolers, traders, and staff members show, more or less, stable social preferences, the stock of nonpooler cooperativeness declines with experience.

\footnotetext{
${ }^{15}$ We had to drop age from the anlaysis because it is highly correlated $(\rho=\mathbf{0 . 7 7})$ with experience.
} 
We also report job category marginal effects after accounting for the differential impact of experience in parentheses in column (4) of Table 2. As one can see, accounting for the treatment effect of the incentives inherent in these jobs further reduces the differences in the job category point estimates. We take this as further evidence that competition on-the-job affects worker social preferences. Our analysis suggests the just three things: the combination of our controls for personality, the competitive perceptions of our participants, and the differential treatment effect of experience on the job almost completely explain the large differences in cooperation that we saw at the outset of our analysis.

\section{Concluding Remarks}

Our field experiment with workers from the fishing community of Toyama Bay provides evidence supporting a standard prediction of tournament theory and the theory of on-the-job competition more generally. Material incentives that promote competition on the job and the resulting perceptions of competition held by workers are associated with lower levels of cooperation between workers. Putting this result in context, the extent to which this link between competition and cooperation is important will obviously vary with the importance of team production because managers will face only small tradeoffs between more intense individual effort and lower synergistic effects when tournaments are set up under a piece rate system, for example. However, when team production is essential, promoting competition among workers may be counterproductive. Indeed, in related work (Carpenter and Seki, 2004) where we limit attention to the fishing members of this community for which we have productivity data, we find that the return to social preferences for cooperation are quite high in an environment where team production is important.

\section{Appendix - Experiment Instructions (Back- translation from Japanese)}

Thank you very much for participating in the exercise today. You will be asked to repeat the exercise 10 times. After that we request that you respond to a brief questionnaire.

In the experiment, you will earn money. The amount you will earn depends on the decisions you and everyone else make during the exercises. This experiment aims to study individual behavior when money is at stake, thus we will use real money during the exercises. You will win the money that you earn during the experiment.

Any decisions you make in the exercises or responses you give in the questionnaire will be strictly confidential. We will never tell anyone your responses or choices. To assure your responses are confidential, we ask you to not speak to each other until the entire experiment is completed.

Rules of the exercise: 
Please check to make sure that the following items are in front of you: A pencil, instructions (this paper), and a large brown envelop.

The exercise will be repeated 10 times but a new rule will be applied for the last 5 times. We will explain new rule before the 6 th round.

You are a member of a group of four people: there are three other people in the group with you. You will all stay in the same group for each of the 10 periods.

To understand the exercise, imagine yourself in a situation where you have to decide how to allocate resources intended for fishing. You may allocate your money to buy new fishing equipment or to build a lighthouse. If you buy new equipment, you will be able to increase your catch and income. If a lighthouse is built, it will help increase the catch and income of all fishers regardless of whether they allocate money for building the lighthouse or not.

In the exercise, you will be asked to decide how much of your money to keep and how much to allocate towards a group project.

At the beginning of each round, we will give you a white envelope with ten 50 yen coins inside. Each person in the group will then decide privately how many of these 10 coins to allocate to a group project and how many to keep for himself or herself. Everyone in the group benefits equally from the money allocated to the group project, but only you benefit from the money you keep. Please put the money you would like to keep in the brown envelop and return the rest that you would like to allocate to the group project in the white envelop. We will collect the white envelope. Please keep the brown envelop with you during the experiment.

When all four members of the group have decided how many coins to allocate to the group project, we will add up all the money from the four group members. When we know the total, we will double it. Each person will then receive an equal share of the doubled amount. Each person also keeps what ever money he or she put in the large brown envelope.

Here is an example to illustrate how the experiment works. Each person decides how much to allocate to the group project privately, so you will not know what anyone else has decided when you make your choice. Suppose that in the first round everyone in your group, including yourself, allocate all 10 coins to the group project. In total there are $10+10+10+10=40$ coins in the group project. The group project will double this amount which makes the total 80 coins. Each of you then receives an equal share, i.e., 20 coins.

To continue the example, let us now suppose in the second round. Everyone in the group receives another 10 coins at the beginning of the round. Imagine that this time everyone in the group contributes no money to the group project. In total there are $0+0+0+0=0$ coin in the group project. Because nobody contributes to the group project, nobody receives anything from the group project. Each person's earnings for round two are just the 10 coins that each person kept.

Let's continue the example for one more round. Now say that you allocate nothing to the group project and the other three people in the same group allocate everything to the group project. The group project will receive a total 
of $0+10+10+10=30$ coins. We double this amount which makes the total of 60 coins. Each person receives an equal share of the 60 coins, i.e., 15 coins from the group project.

In the round 3 you would earn total of 25 coins ( 15 from the group project plus the 10 you kept), while the other members will earn 15 coins from the project.

After each round, you will be provided with an allocation report that contains all four members' allocation to the group project in an random order, total number of coins allocated to the project, and your share of income from the group project. Please note that group members' allocations are written in a random order so that it is impossible to identify who allocate how much money to the project.

The above is only an example. You will play 5 rounds and each of you will decide, on your own, how to allocate the 10 coins that you receive at the beginning of each round.

Are there any questions about how the experiment will proceed?

Rules for exercise 2 (only to be handed out after exercise 1 has been completed)

Exercise 2 is very similar to exercise 1 , but there will be one difference in the procedures.

The first part of each decision making round will be exactly the same as exercise 1 . There will be 5 decision making rounds and you will each receive 10 coins at the beginning of each round. You will decide privately how much money to allocate to the group project and how much to keep. When everyone in the group has made this decision, we will calculate the total contribution. We will then double the total contribution. Each person will receive an equal share of the doubled amount.

The only difference between exercise 1 and exercise 2 is you will have the possibility to send a message to the rest of your group. This is the message you can send:

\section{show "unhappy face"}

You will be asked to fill out an order form for an "unhappy face" after each round. We will collect the order forms and count the number of "unhappy face" marks ordered in each group. At the beginning of the next round, the white envelop that you receive will have the number of unhappy face marks ordered by your group on it.

Please note that ordering the "unhappy mark" will cost you 10 yen. When you see stamps on your envelop, you know that some of the group members have spent 10 yen each to tell the rest of the group that they are unhappy with the amount that was allocated to the group project by the group. Anyone who decides to send this message will do so anonymously. Nobody will know who sent the messages.

Are there any questions about how the exercise will proceed? 


\section{Tables and Figures}

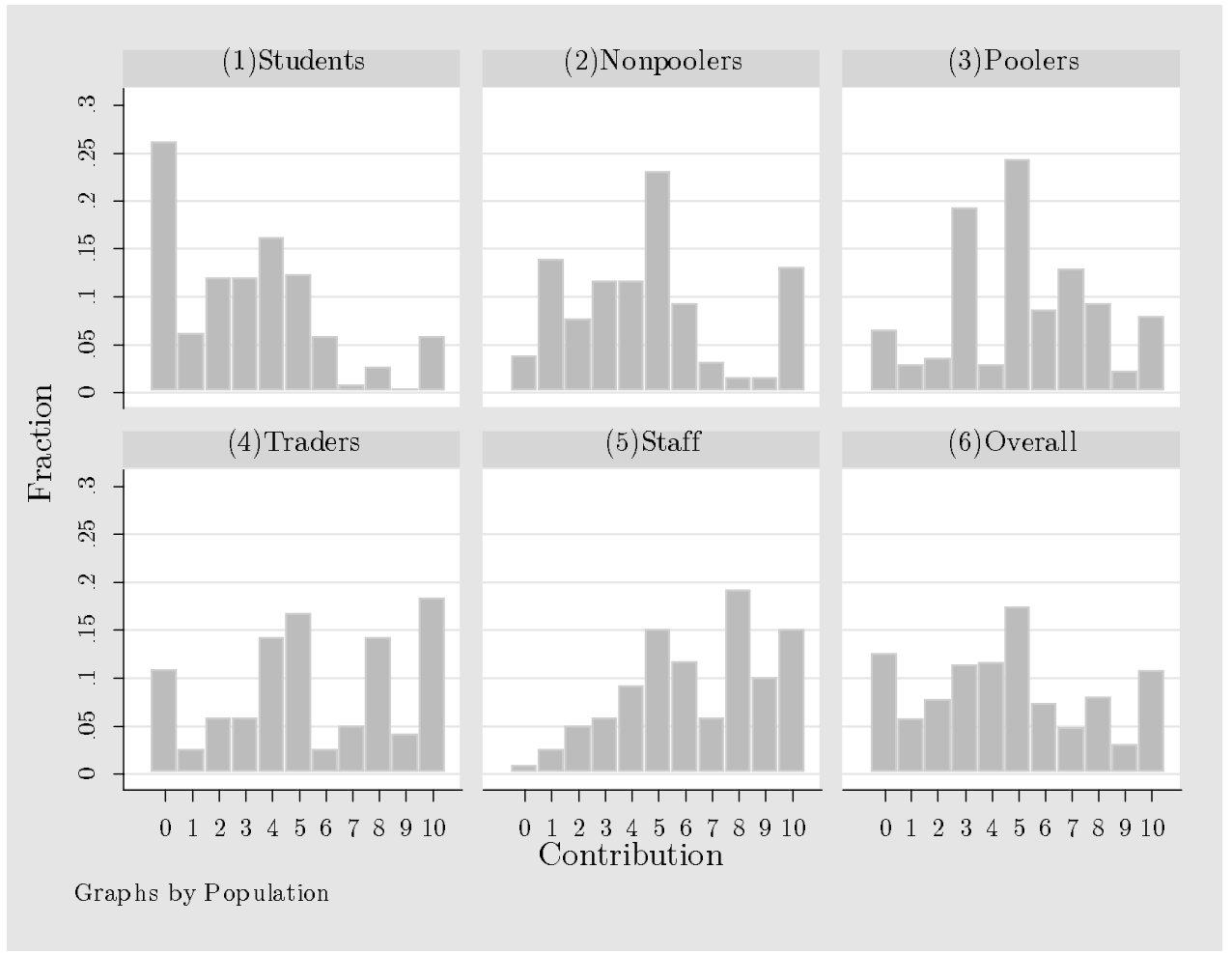

Figure 1: Contribution Histograms (pooling the data over all ten rounds). 


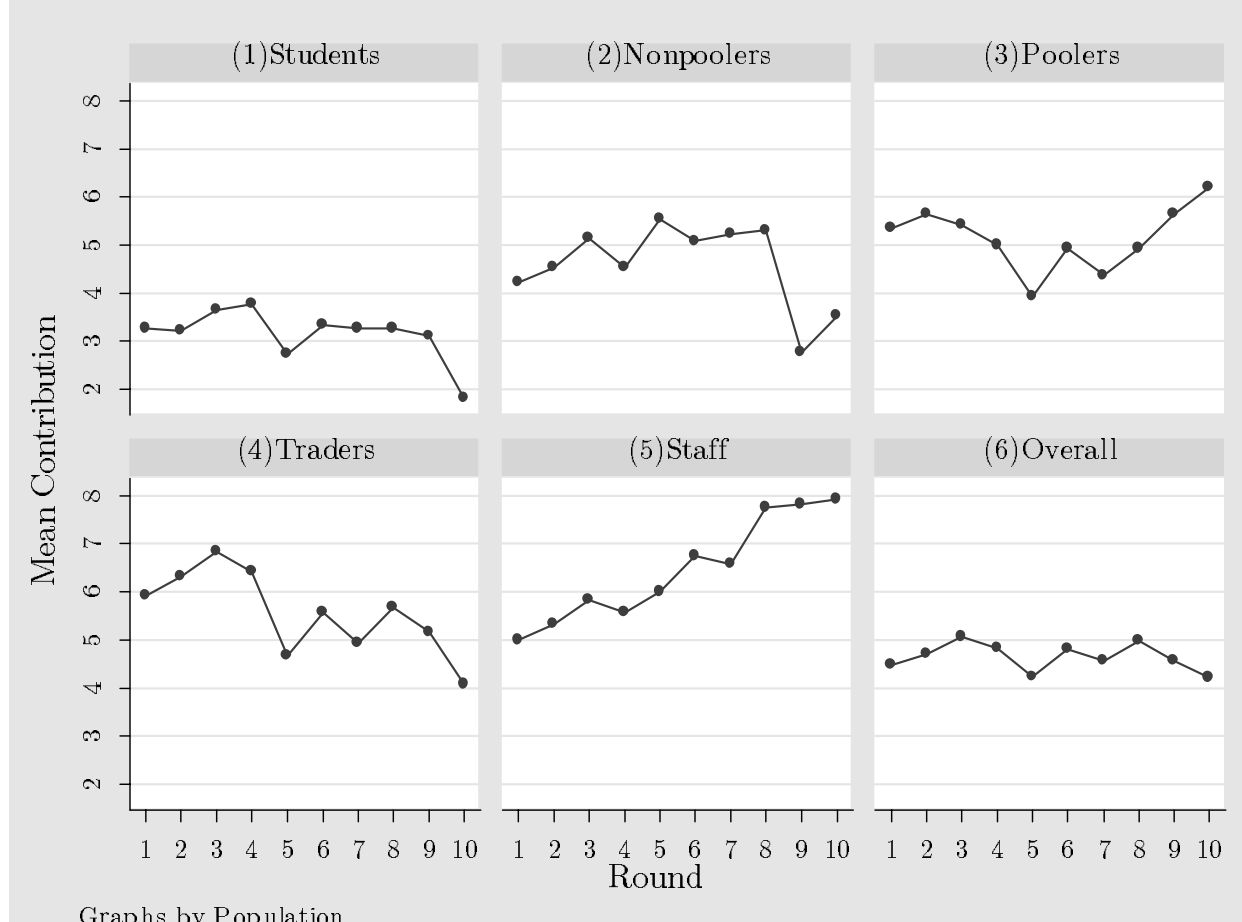

Figure 2: Contribution Time Series. 


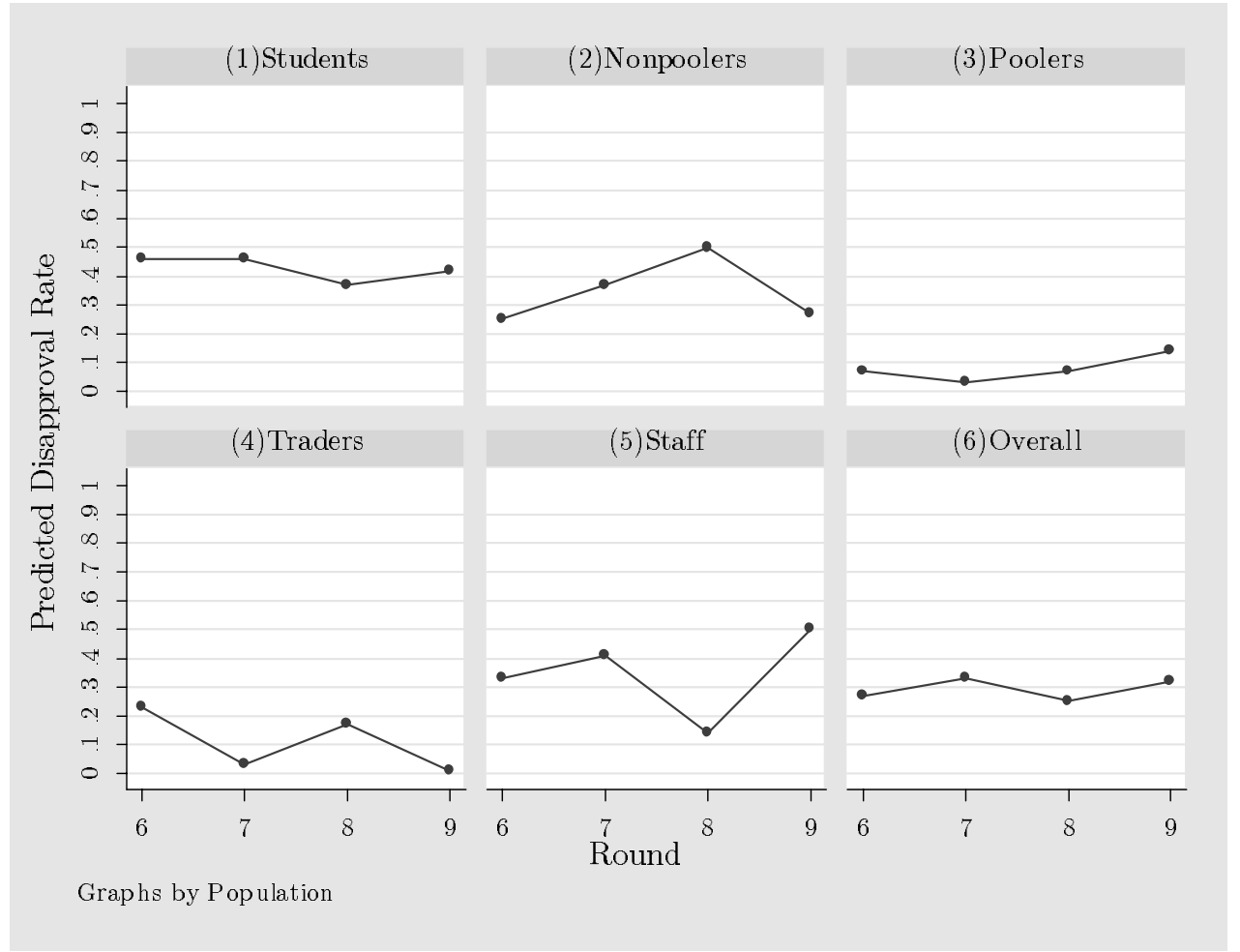

Figure 3: Time Series on the Probability of Social Disapproval (controlling for how much the other group members contributed).

\begin{tabular}{lcccccc}
\hline & \multicolumn{1}{c}{ TABLE 1: PARTICIPANT CHARACTERISTICS BY POPULATION } & & \\
\hline & Students & Nonpoolers & Poolers & Traders & Staff & Overall \\
Participants & 26 & 13 & 14 & 12 & 12 & 77 \\
Female (fraction) & 0.35 & 0.38 & 0 & 0.08 & 0.25 & 0.23 \\
Age (mean) & 21.35 & 53.54 & 49.78 & 35.00 & 34.16 & 36.08 \\
High (or Occupational) School (fraction) & 0 & 0.46 & 0.46 & 0.58 & 0.67 & 0.36 \\
Rotter Score (mean) & 0.61 & -0.23 & 0.78 & -0.75 & 0.33 & 0.25 \\
Cooperation Scale (mean) & 0.38 & 0.50 & 1.07 & 0.25 & 0.25 & 0.47 \\
\hline
\end{tabular}




\begin{tabular}{|c|c|c|c|c|}
\hline \multicolumn{5}{|c|}{$\begin{array}{l}\text { TABLE 2: CONTRIBUTION DECISIONS } \\
\text { (dependent variable is Contribution }{ }_{i, t} \text { ) }\end{array}$} \\
\hline & (1) & (2) & (3) & (4) \\
\hline \multirow[t]{2}{*}{ Nonpoolers } & 2.06 & 1.99 & 2.41 & $14.35(2.46)$ \\
\hline & {$[0.65\rfloor^{* * * *}$} & {$[1.04\rfloor^{* *}$} & {$[0.98]^{* *}$} & {$[4.57]^{* * * *}$} \\
\hline \multirow[t]{2}{*}{ Traders } & 2.99 & 2.84 & 3.10 & $11.71(2.20)$ \\
\hline & {$[0.66]^{* * * *}$} & {$[0.85]^{* * * *}$} & {$[0.80]^{* * * *}$} & {$[4.50]^{* * * *}$} \\
\hline \multirow[t]{2}{*}{ Poolers } & 2.45 & 2.57 & 2.65 & $11.15(1.64)$ \\
\hline & $|0.62|^{* * * *}$ & {$[0.99]^{* * * *}$} & $|0.93|^{* * * *}$ & {$[4.46]^{* * *}$} \\
\hline \multirow[t]{2}{*}{ Staff } & 4.02 & 4.22 & 4.00 & $12.29(2.96)$ \\
\hline & {$[0.66]^{* * * *}$} & {$[0.83]^{* * *}$} & {$[0.78]^{* * *}$} & {$[4.43]^{* * *}$} \\
\hline \multirow[t]{2}{*}{ Disapproval Allowed } & & -0.40 & -0.40 & 0.03 \\
\hline & & {$[0.52]$} & {$[0.52]$} & {$[0.54]$} \\
\hline \multirow[t]{2}{*}{ Female } & & 0.06 & 0.13 & 0.37 \\
\hline & & $\lfloor 0.53\rfloor$ & $\lfloor 0.50\rfloor$ & $\lfloor 0.54\rfloor$ \\
\hline \multirow[t]{2}{*}{ Age } & & 0.12 & 0.19 & \\
\hline & & $\lfloor 0.10\rfloor$ & {$[0.09]^{* * *}$} & \\
\hline \multirow[t]{2}{*}{$\mathrm{Age}^{2}$} & & -0.001 & -0.002 & \\
\hline & & {$[0.001]$} & {$[0.001]^{* *}$} & \\
\hline \multirow[t]{2}{*}{ High (or Occupational) School } & & -0.67 & -0.65 & -0.49 \\
\hline & & {$[0.59\rfloor$} & {$[0.55\rfloor$} & $\lfloor 0.51\rfloor$ \\
\hline \multirow[t]{2}{*}{ Rotter Score } & & -0.16 & -0.23 & -0.14 \\
\hline & & {$[0.10\rfloor$} & {$[0.10]^{* *}$} & $\lfloor 0.10\rfloor$ \\
\hline \multirow[t]{2}{*}{ Cooperation Scale } & & 0.33 & 0.41 & 0.22 \\
\hline & & {$[0.21]$} & {$[0.20]^{* *}$} & {$[0.21]$} \\
\hline \multirow[t]{2}{*}{ Competitive Work Environment } & & & -1.53 & -1.27 \\
\hline & & & {$[0.47]^{* * * *}$} & {$[0.45]^{* * *}$} \\
\hline \multirow[t]{2}{*}{ Experience } & & & & 0.53 \\
\hline & & & & {$[0.30]^{*}$} \\
\hline \multirow[t]{2}{*}{ Experience $\times$ Nonpooler } & & & & -0.65 \\
\hline & & & & $\mid 0.30]^{* *}$ \\
\hline \multirow[t]{2}{*}{ Experience $\times$ Traders } & & & & -0.52 \\
\hline & & & & {$[0.31]^{*}$} \\
\hline \multirow[t]{2}{*}{ Experience $\times$ Poolers } & & & & -0.52 \\
\hline & & & & {$[0.30]^{*}$} \\
\hline \multirow[t]{2}{*}{ Experience $\times$ Staff } & & & & -0.51 \\
\hline & & & & {$[0.30]^{*}$} \\
\hline \multirow[t]{2}{*}{ Constant } & 2.49 & 0.53 & -0.68 & -5.74 \\
\hline & $|0.51|^{* * * *}$ & $\lfloor 1.71\rfloor$ & $\lfloor 1.65\rfloor$ & $\lfloor 4.44\rfloor$ \\
\hline$\overline{\text { rho }}$ & 0.21 & 0.19 & 0.16 & 0.15 \\
\hline Round Fixed Effects & yes & yes & yes & yes \\
\hline Obs. & 770 & 760 & 760 & 670 \\
\hline Log Likelihood & -1746 & -1721 & -1716 & -1510 \\
\hline
\end{tabular}




\begin{tabular}{|c|c|c|c|c|}
\hline \multicolumn{5}{|c|}{$\begin{array}{l}\text { TABLE 3: SOCIAL DISAPPROVAL DECISIONS } \\
\text { (dependent variable is } 1 \text { if disapproval is shown by } i \text { in round } t \text { ) }\end{array}$} \\
\hline & (1) & (2) & (3) & (4) \\
\hline \multirow[t]{2}{*}{ Total Contribution of Others } & -0.03 & -0.02 & -0.02 & -0.02 \\
\hline & {$[0.02\rfloor$} & $\lfloor 0.02\rfloor$ & $\lfloor 0.02\rfloor$ & {$[0.02]$} \\
\hline \multirow[t]{2}{*}{ Nonpoolers } & -0.43 & -2.63 & -2.87 & -2.81 \\
\hline & {$[0.49]$} & {$[0.98]^{* * *}$} & {$[1.01]^{* * *}$} & {$[0.99] * * *$} \\
\hline \multirow[t]{2}{*}{ Traders } & -1.00 & -2.55 & -2.65 & -2.57 \\
\hline & {$[0.60]^{*}$} & {$[0.87]^{* * *}$} & {$[0.87]^{* * *}$} & {$[0.85]^{* * *}$} \\
\hline \multirow[t]{2}{*}{ Poolers } & -1.28 & -3.38 & -3.43 & -3.33 \\
\hline & {$[0.56]^{* *}$} & {$[0.98]^{* * *}$} & {$[0.97]^{* * *}$} & {$[0.95] * * *$} \\
\hline \multirow[t]{2}{*}{ Staff } & 0.15 & -1.02 & -1.03 & -1.21 \\
\hline & {$[0.57]$} & {$[0.72]$} & {$[0.72]$} & {$[0.72]^{*}$} \\
\hline \multirow[t]{2}{*}{ Female } & & -0.30 & -0.28 & -0.17 \\
\hline & & {$[0.39]$} & {$[0.39]$} & {$[0.39]$} \\
\hline \multirow[t]{2}{*}{ Age } & & 0.16 & 0.14 & 0.14 \\
\hline & & {$[0.08]^{* *}$} & {$[0.08]^{*}$} & {$[0.08]^{*}$} \\
\hline \multirow[t]{2}{*}{$\mathrm{Age}^{2}$} & & -0.001 & -0.001 & -0.001 \\
\hline & & {$[0.001]$} & {$[0.001]$} & {$[0.001]$} \\
\hline \multirow[t]{2}{*}{ High (or Occupational) School } & & 0.14 & 0.14 & 0.07 \\
\hline & & {$[0.48]$} & {$[0.48]$} & {$[0.48]$} \\
\hline \multirow[t]{2}{*}{ Rotter Score } & & -0.10 & -0.07 & -0.06 \\
\hline & & {$[0.09]$} & {$[0.09]$} & {$[0.09]$} \\
\hline \multirow[t]{2}{*}{ Cooperation Scale } & & 0.21 & 0.18 & 0.18 \\
\hline & & {$[0.17]$} & {$[0.17]$} & {$[0.16]$} \\
\hline \multirow[t]{2}{*}{ Competitive Work Environment } & & & 0.58 & \\
\hline & & & {$[0.41]$} & \\
\hline \multirow[t]{2}{*}{ Consider Others Family } & & & & 0.04 \\
\hline & & & & {$[0.63]$} \\
\hline \multirow[t]{2}{*}{ Consider Others Friends } & & & & -0.73 \\
\hline & & & & {$[0.42]^{*}$} \\
\hline rho & 0.58 & 0.52 & 0.50 & 0.49 \\
\hline Round Fixed Effects & yes & yes & yes & yes \\
\hline Obs. & 308 & 304 & 304 & 304 \\
\hline Log Likelihood & -157 & -151 & -150 & -149 \\
\hline
\end{tabular}




\begin{tabular}{rccccc}
\hline \multicolumn{5}{c}{ TABLE 4: SURVEYED LEVELS OF INGROUP COMPETITION } \\
(frequency categorizing others by population) \\
\hline Consider fellow workers as: & Students & Nonpoolers & Traders & Poolers & Staff \\
Family & 0.08 & 0.00 & 0.00 & 0.21 & 0.42 \\
Friends & 0.88 & 0.31 & 0.50 & 0.43 & 0.50 \\
Strangers & 0.04 & 0.15 & 0.08 & 0.21 & 0.08 \\
Competitors & 0.08 & 0.69 & 0.42 & 0.14 & 0.42 \\
\hline Level of Work Competition: & & High & High & Medium & Low \\
\hline
\end{tabular}

\begin{tabular}{cccc}
\hline \multicolumn{3}{c}{ TABLE 5: COMPARISON OF CONTRIBUTION POINT ESTIMATES } \\
\hline Staff & Traders & Poolers \\
Nonpoolers & $\chi^{2}=7.07^{* * *} \mid \chi^{2}=3.82^{*}$ & $x^{2}=1.00 \mid \chi^{2}=0.74$ & $\chi^{2}=0.59 \mid \chi^{2}=0.10$ \\
Poolers & $\chi^{2}=3.99^{* *} \mid \chi^{2}=3.02^{*}$ & $x^{2}=0.10 \mid \chi^{2}=0.34$ & - \\
Traders & $\chi^{2}=3.21^{*} \mid \chi^{2}=1.50$ & - & - \\
\hline
\end{tabular}

Notes: First value is based on regression (2) in Table 2. Second value is based on regression (3) in Table 2. * indicates significant at $10 \%, * *$ at $5 \%$, and $* * *$ at $1 \%$.

\begin{tabular}{cccc}
\hline \multicolumn{3}{c}{ TABLE 6: COMPARISON OF DISAPPROVAL POINT ESTIMATES } \\
\hline Staff & Traders & Poolers \\
Nonpoolers & $\chi^{2}=5.12^{* *} \mid \chi^{2}=4.72^{* *}$ & $\chi^{2}=0.01 \mid \chi^{2}=0.12$ & $\chi^{2}=1.56 \mid \chi^{2}=0.77$ \\
Poolers & $\chi^{2}=10.26^{* * *} \mid \chi^{2}=8.52^{* * *}$ & $\chi^{2}=1.34 \mid \chi^{2}=1.21$ & - \\
Traders & $\chi^{2}=4.95^{* *} \mid \chi^{2}=3.93^{* *}$ & - & - \\
\hline
\end{tabular}

Notes: First value is based on regression (2) in Table 3 . Second value is based on regression (4) in Table $3 . *$ indicates significant at $10 \%, * *$ at $5 \%$, and $* * *$ at $1 \%$. 


\section{References}

Bandiera, O., Barankay, I., Rasul, I., 2004. Cooperation in the workplace: Evidence from the field. London School of Economics, Working Paper.

Burks, S., Carpenter, J., Goette, L., 2005. Performance pay and the erosion of worker cooperation: Field experimental evidence. Department of Economics, Middlebury College Working Paper.

Carpenter, J., 2005. Endogenous social preferences. Review of Radical Political Economy. 37, 63-84.

Carpenter, J., Daniere, A., Takahashi, L., 2004a. Cooperation, trust, and social capital in southeast Asian urban slums. Journal of Economic Behavior \& Organization. 55, 533-551.

Carpenter, J., Daniere, A., Takahashi, L., 2004b. Social capital and trust in southeast Asian cities. Urban Studies. 41, 853-874.

Carpenter, J., Harrison, G., List, J., 2005. Field experiments in economics: An introduction. In: Carpenter, J., Harrison, G., List, J. (Eds.), Field experiments in economics, JAI/Elsevier, Greenwich, Conn, and London, pp. 1-16.

Carpenter, J., Seki, E., 2004. Do social preferences increase productivity? Field experimental evidence from fishermen in Toyama bay. Department of Economics, Middlebury College Working Paper.

Chen, K.-P., 2003. Sabotage in promotion tournaments. Journal of Law, Economics, and Organization. 19, 119-140.

Drago, R., Garvey, G.T., 1998. Incentives for helping on the job: Theory and evidence. Journal of Labor Economics. 16, 1-25.

Harrison, G., List, J., 2004. Field experiments. Journal of Economic Literature. 42, 1009-1055.

Hasegawa, Y., Sato, M., Yamamoto, T., 1991. Fisheries cooperative as the core for development of coastal fisheries management system - Japanese experiences. In: Yamamoto, T., Short, K. (Eds.), International perspectives on fisheries management - with special emphasis on community-based management systems developed in Japan, proceedings of the jifs/iifet/zengyoren symposium on fisheries management, National Federation of Fisheries Cooperative Associations (Zengyoren), Tokyo.

Holmstrom, B., Milgrom, P., 1991. Multitask principal-agent analyses: Incentive contracts, asset ownership, and job design. Journal of Law, Economics, and Organization. 7, 24-52.

Kiyonari, T., Tanida, S., Yamagishi, T., 2000. Social exchange and reciprocity: Confusion or a heuristic? Evolution \& Human Behavior. 21, 411-427.

Lazear, E.P., 1989. Pay equality and industrial politics. Journal of Political Economy. 97, 561-580.

Ledyard, J., 1995. Public goods: A survey of experimental research. In: Kagel, J., Roth, A. (Eds.), The handbook of experimental economics, Princeton University Press, Princeton, pp. 111-194. 
List, J., 2004. Young, selfish and male: Field evidence of social preferences. The Economic Journal. 114, 121-149.

Masclet, D., Noussair, C., Tucker, S., Villeval, M.-C., 2003. Monetary and nonmonetary punishment in the voluntary contributions mechanism. American Economic Review. 93, 366-380.

Platteau, J., Seki, E., 2001. Community arrangements to overcome market failure: Pooling groups in Japanese fisheries. In: Aoki, M., Hayami, Y. (Eds.), Community and market in economic development, Clarendon Press, Oxford, pp. 344-402.

Rob, R., Zemesky, P., 2002. Social Capital, corporate culture, and incentive intensity. Rand Journal of Economics. 33, 243-257.

Rottemberg, J., 1994. Human relations in the workplace. Journal of Political Economy. 102, 684-717.

Rotter, J.B., 1966. Generalized expectancies for internal versus external control of reinforcement. Psychological Monographs; General and Applied. 80 , $1-28$.

Seki, E., forthcoming. Effects of rotation scheme on fishing behavior with price discrimination and limited durability: Theory and evidence. Journal of Development Economics.

Yamagishi, T., 1986. The provision of a sanctioning system as a public good. Journal of Personality and Social Psychology. 51, 110-116.

Yamamoto, T., Short, K., (Eds.) (1991) International perspectives on fisheries management - with special emphasis on community-based management systems developed in Japan, proceedings of the jifs/iifet/zengyoren symposium on fisheries management. National Federation of Fisheries Cooperative Associations (Zengyoren), Tokyo. 